[Regular Paper]

\title{
Estimation of Coke and Metal Deposition Distribution within Hydrodesulfurization Catalyst Pore at the Last Stage of Operation
}

\author{
Kazuo IDEI $^{\dagger 1)}$, Takeshige TAKAHASHI ${ }^{\dagger 2) *}$, and Takami KAI ${ }^{\dagger 2}$ \\ ${ }^{\dagger 1)}$ Research \& Development Center, Cosmo Oil Co., Ltd., Gongendo 1134-2, Satte, Saitama 340-0193, JAPAN \\ ${ }^{\dagger 2}$ Dept. of Applied Chemistry and Chemical Engineering, Faculty of Engineering, Kagoshima University, \\ Korimoto 1-21-40, Kagoshima 890-0065, JAPAN
}

(Received July 12, 2002)

\begin{abstract}
Hydrodesulfurization (HDS) of atmospheric residue (AR) carried out over Ni-Mo or Co-Mo catalyst requires a sudden increase in the reaction temperature for the desired desulfurization at the end of operation (EOR). This phenomenon is mainly caused by reduced diffusion rate due to metal deposition in the pore mouth. The present study performed HDS over catalysts with different pore size to separately examine the effects of metal and coke deposition on catalyst deactivation. HDS catalysts used in a commercial process for 1 year were analyzed by EPMA to determine the coke and metal distribution along the catalyst radius. A model equation was developed to quantitatively estimate the coke and metal distribution. The model equation could estimate parameters such as Thiele modulus and catalyst properties coefficient. Furthermore, the equation was applicable to used catalyst obtained from commercial equipment and to used catalysts with different pore radii after HDS of Boscan crude containing large amounts of metals and asphaltenes. The distributions of coke and metals could be simulated with the model equation, giving 0.01 and 4 for the Thiele moduli for coke and metal, respectively. The model equation developed in this study is useful to estimate the service life of HDS catalyst.
\end{abstract}

\section{Keywords}

Hydrodesulfurization, Model equation, Thiele modulus, Metal distribution estimation,

Coke distribution estimation

\section{1. 緒言}

近年，常圧残油を原料油とする水素化脱硫プロセス（HDS） は，低硫黄重油の製造，流動接触分解（FCC）に供給する原料 油の前処理，灯油抢よび軽油の増産を目的とした水素化分解な ど使用形態が多様化しており, これらの要求に対応するため高 性能触媒の開発と触媒寿命推定技術の高度化が求められてい る。HDS ではアルミナに担持されたコバルトーモリブデンある いはニッケルーモリブデン触媒が広く用いられているが，活性 劣化の挙動は原料油種, 触媒種揖よび HDS 処理条件により著 しく異なる。

一般的に, 常圧残油（AR）の HDS プロセスでは反応初期 （SOR: Start of Run）に急速な活性低下が起こり，反応中期 (MOR: Middle of Run) で安定した後, 反応後期 (EOR: End of Run）において再び急激な活性低下が起こる。この劣化挙動は 極めて複雑であるが，定性的には以下の原因によるものと考元 られている11,2)。すなわち，SORにおける急激な活性低下はコ ークたい積による活性点の減少が，MORに扔ける安定的な活 性低下はメタルたい積による拡散速度の低下が，そして EOR における急激な活性低下はコークとメタルの同時たい積による

* To whom correspondence should be addressed.

* E-mail: takahashi@cen.kagoshima-u.ac.jp
細孔閉そくが原因である。触媒寿命を予測することは商業運転 上，非常に重要であることから，細孔閉そくモデル等から数多 くの触媒寿命を予測する方法が提案されてきた3) 6)。しかしな がら，これらのモデルの多くはメ夕ルのみによる触媒劣化に主 眼が置かれ, SOR から EOR までの活性劣化を推定するには不 十分であった。

著者らは, 重質油の HDS 反応における触媒劣化挙動をコー クおよびメタルたい積による活性点と触媒有効係数の減少であ ると考え，この二つの要因が関与していることを想定した総括 劣化速度式を提案した ${ }^{7,8)}$ 。この速度式は複雑な直接脱硫触媒 の劣化挙動を実測可能な六つのパラメーターで簡単に表現でき る特徵を持っている。本モデルを用いて細孔径の異なる HDS の劣化挙動を解析したところ, 劣化速度式を構成するパラメー ターと触媒物性との間に相関があることが分かった。そこで, 活性劣化に及ぼすコーク抢よびメタルの影響を分離して評価す る目的で, 平均細孔径の異なる触媒によるHDS 反応および商 業装置で 1 年間使用した触媒の残余活性の測定を行った ${ }^{9), 10)}$ そして, 使用済触媒のキャラクタリゼーションからコークおよ びメタルの密度とたい積層厚さを算出し, SOR から MORに押 ける触媒物性と活性劣化に対するそれぞれの影響を定量的に明 らかにした。

筆者らが提案した総括劣化速度式は, EOR で観測される急 
激な劣化挙動を触媒有効係数と活性がなくなるまでの反応経過 時間（触媒寿命と定義）の二つのパラメーターで表現できる特 徵を持っている。これらのパラメーターは実測できるが, 触媒 物性と関連づけて推定できればより一般化されたモデルに発展 させることができると考えられる。当然のことであるが，実装 置では種々の性質の異なる常圧残さ油を供給し, さらに触媒の 活性低下とともに反応温度を上げる操作が行われる。しかしな がら, SOR から EOR まで連続的な操作が行われるため, 触媒 劣化挙動を連続的に表す式が必要である。

本研究では触媒有効係数と触媒物性の変化を相関する目的 で，拡散理論を応用して細孔閉そく現象を定量化することを試 みた。今回提案するモデルでは細孔を単純な円柱と仮定し，触 媒有効係数を導入するため, 触媒細孔内のコークおよびメ夕ル 分布を定量的に取り扱うためのたい積層分布関数を導出した。 そして，これまでに得られた使用済触媒のデータからコークお よびメタルたい積量と触媒物性の変化量の関係を一般化し, こ れらのたい積量から触媒物性を推定する方法を提案した。さら に, 本モデルを使用済触媒に適用して解析された結果と EPMA (electron probe micro analysis) で観測されたコークおよ びメタル分布を比較することにより，モデルの有効性について 検討した。

\section{2. 実 験方法}

\section{1. 供試触媒}

本研究では, 前報と同様に平均細孔径の異なる 3 種類の触媒 を組み合わせて使用し， 2 種類の常圧残油，すなわちアラビア ンライトから得られた残油 (AL-AR) 拉よびイラニアンヘビ 一から得られた残油（IH-AR）の HDS 反応を評価日数を変え て行い,コークおよびメタルたい積量を調整した使用済触媒を 得た ${ }^{9)}$ 。これとともに商業装置で 1 年間使用した脱硫触媒を用 いた ${ }^{10)}$ 。これらの触媒の物性ならびにコークおよびメタルたい 積量については, 既に報告したので省略する9),10)。さらに, メ タルによる加速劣化試験として, 前報で報告した 3 種類の触媒 を用いて，ボスカン原油 $(\mathrm{Ni}+\mathrm{V}=1420 \mathrm{ppm})$ による HDS 反 応抢よび水素化脱メタル $(\mathrm{HDM})$ 反応を行い, 細孔閉そくが 進行した使用済触媒を得た。

HDS およびHDM 反応に使用した反応装置, 触媒の充填方 法, 反応操作条件等については既に報告したので省略する ${ }^{10)}$ 。

\section{2. 触媒のキャラクタリゼーション}

すべての使用済触媒はソックスレー抽出器を用いて, ベンゼ ンで洗浄後, 減圧乾燥 $\left(100^{\circ} \mathrm{C}, 6\right.$ 時間 $)$ を行い, 各種機器分 析の試料とした。

触媒の比表面積は窒素脱吸着法にて測定し, 細孔容積と平均 細孔径は水銀ポロシメトリー法にて測定した。なお，平均細孔 径（MPD）は, 細孔容積をある值以上の径の部分とそれ以下 の径の部分に均等に 2 分する細孔直径, いわゆる細孔容積の細 孔直径に関する分布のメディアン值として求めた。

金属分析は高周波プラズマ発光金属分析計を用いた。コーク 分析は CHN 分析計で行った。触媒細孔内にたい積したコーク およびメタルの分布はEPMA 装置を用いて測定した。これら の測定法の詳細についても既に報告した(10) ので省略する。

\section{3. 結果および考察}

\section{1. 触媒細孔内のコークおよびメタル分布のシミュレーシ ヨンモデル}

前報に扔いて使用済触媒の EPMA 分析を行った結果, コー クは細孔内にほぼ均一にたい積しているが, メタルは不均一に たい積し, 触媒の外表面部近傍に偏析していることが観察され た ${ }^{10)}$ 。このことから, 脱メタル反応は細孔の入口近傍で進行す ることが示唆され，入口近傍でたい積したメタルにより反応物 質の拡散が妨げられる，いわゆる細孔閉そくが生じていると考 えられた。さらに, この細孔閉そく現象を厳密に取り扱うため には拡散阻害を考慮した触媒の活性劣化モデルが必要であるこ とが分かった。

一方，著者らはこれまでにHDS 反応におけるSORから EOR までの触媒劣化挙動を表現できる Eq. (1)の総括劣化速度 式を提案した8)。

$$
\begin{aligned}
\ln \Phi_{0}= & -\left[\ln \frac{k^{0}}{k_{1}^{0}}+\alpha_{1} t\right]+\ln \left[1+\frac{k_{2}^{0}}{k_{1}^{0}} \exp \left(\alpha_{1}-\alpha_{2}\right) t\right] \\
& -\left[\frac{\ln \left[\eta_{0}^{2}+\left(1-\eta_{0}^{2}\right) /\left(1-t / t_{\infty}\right)\right]}{2}\right]
\end{aligned}
$$

ここで, $\Phi_{0}$ は活性の減少割合, $k_{1}^{0}$ は容易に失活する活性点 による反応初期の速度定数, $k^{0}$ は全活性点による初期速度定 数, $k_{2}^{0}$ は失活しにくい活性点による反応初期の速度定数, $\alpha_{1}$ は容易に失活する活性点の劣化定数, $\alpha_{2}$ は失活しにくい活性 点の劣化定数, $\eta_{0}$ は新触媒の有効係数, $t$ は反応経過時間, そ して $t_{\infty}$ は触媒寿命である。なお, 一般に触媒寿命は半減期, 装置運転限界温度あるいは製品品質などの制約条件を満足する 時間で定義されるが, 本モデルでは活性がほとんど失われた状 態になるまでの反応時間を触媒寿命と定義した。

拡散阻害による活性劣化は, Eq. (1)の右辺第 3 項で示され る。この項は反応経過に伴ってたい積するコークおよびメタル により反応物が活性点へ接近できる領域が次第に減少して行 き, 細孔閉そくを起こして触媒寿命に達するまでの挙動を $\eta_{0}$ と $t_{\infty}$ 二つのパラメーターで表現している。

ここでは, 現在まで得られた知見をもとに, コークおよびメ タルたい積量による触媒物性の変化を定量的に表すモデルを提 案するとともに, EORに扔ける急速な活性劣化の原因である 細孔閉そく現象を細孔径の変化から推算するモデルを提案す る。

細孔内のたい積物分布をモデル化するにあたって, 前述した ように細孔はFig. 1 に示すように均一な直径をもつ円柱と仮 定した。これを平均細孔径モデルと名づける。Fig. 1 の平均細 孔径モデルにおいて，たい積物の無次元容積 $\left(V_{\mathrm{D}} / V_{0}\right)$ は Eq. (2) で与えられる。

$$
\frac{V_{\mathrm{D}}}{V_{0}}=\frac{\pi r_{0}^{2}}{2 \pi r_{0}^{2} L}\left\{2 L-2 \int_{0}^{L}\left(1-\frac{\lambda_{x}}{r_{0}}\right)^{2} \mathrm{~d} x\right\}
$$

ここで $r_{0}$ は新触媒の平均細孔半径, $L$ は触媒の相当半径, $\lambda_{x}$ は距離 $x$ に扔けるたい積物の厚さを表す。たい積物の生成反応 が細孔内拡散律速であるとすると, 1 次反応における触媒有効 係数 $(\eta)$ は Eq. (3)で表される。

$$
\eta=\tan h(m L) / m L
$$

ここで $m L$ はq. (4)で定義されるチイレ数（Thiele modulus） 


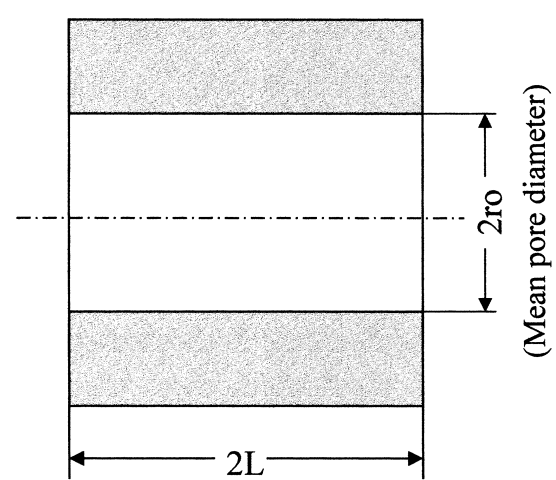

(Pellet size)

Fresh Catalyst

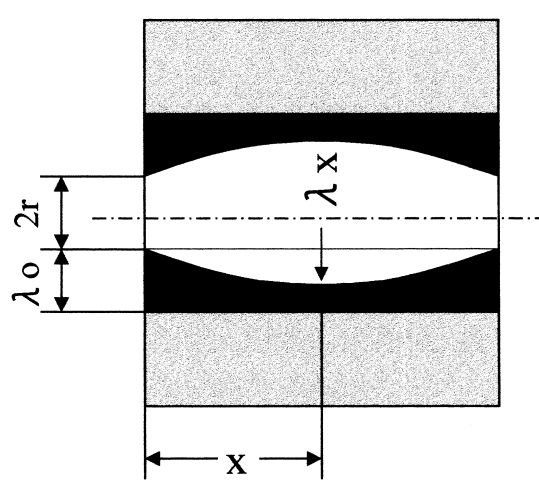

Used Catalyst

Fig. 1 Schematic Diagram of Model for Blocking of Catalyst Pore Mouth

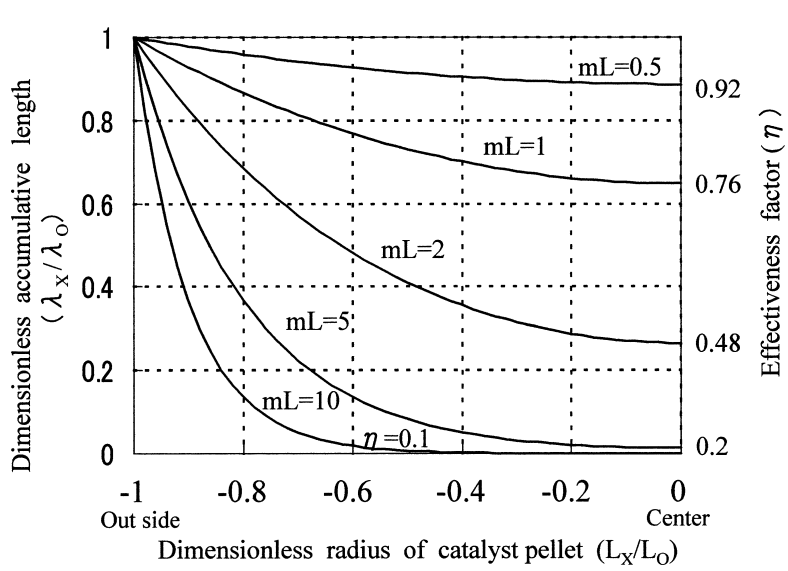

Fig. 2 Effect of Dimensionless Radius on Dimensionless Accumulative Length Calculated from Eq. (5)

である。

$$
m L=L \sqrt{\frac{k}{D}}
$$

Eq. (3)の触媒有効係数をたい積物の生成反応に適用すると, 細孔内のたい積物層厚さ $\lambda_{x}$ は Eq. (5) で表される。ここで, $\lambda_{0}$ は触媒外表面部のたい積層厚さである。

$$
\lambda_{x}=\lambda_{0} \frac{\cos h m(L-x)}{\cos h m L}
$$

Fig. 2 は $m L$ をパラメーターとして, Eq. (5) から計算される入 口のたい積層厚さに対する触媒内部のたい積層厚さの比 $\left(\lambda_{x} / \lambda_{0}\right)$ の計算結果である。チイレ数が増大するに従い, 反応 物質の細孔内への拡散速度よりもたい積物を生成する反応速度 が大きくなり，たい積物は触媒の外表面部近傍に多く偏析する ようになることを示している。

したがって，Fig. 2 に示す関係を平均細孔径モデルに取り入 れると, たい積物の無次元容積 $\left(V_{\mathrm{D}} / V_{0}\right)$ は, Eq. (5) を Eq. (2) に代入し， $x=0$ から $x=L$ まで積分して整理すると Eq. (6)の ようになる。

$$
\frac{V_{\mathrm{D}}}{V_{0}}=\frac{2 \tan h m L}{m L}\left(\frac{\lambda_{0}}{n}\right)-\left(\frac{\tan h m L}{2 m L}+\frac{1}{2 \cos h^{2} m L}\right)\left(\frac{\lambda_{0}}{n}\right)^{2}(6)
$$

Eq. (6) をたい積物の触媒外表面厚さ $\left(\lambda_{0} / r_{0}\right)$ について整理する と, Eq. (7)のようになる。

$$
\frac{\lambda_{0}}{r_{0}}=\frac{B-\sqrt{B^{2}-4 A C}}{2 A} \quad\left(\frac{\lambda_{0}}{r_{0}} \geqq 0\right)
$$

ただし $, A=\frac{\tan h m L}{2 m L}+\frac{1}{2 \cos h^{2} m L}, \quad B=\frac{2 \tan h m L}{m L}, \quad C=\frac{V_{\mathrm{D}}}{V_{0}}$ で ある。ここで, Eq. (3) から Eq. (7)の関係は $n$ 種のたい積物 $(i$ 成分）についてそれぞれ成り立つので, 距離 $x$ における $i$ 成分 のたい積層厚さは Eq. (5)に Eq. (7) を代入して得られる。した がって, $n$ 種のたい積物の総たい積層厚さ $\lambda_{x}$ は, 上記の方法 で得られた $i$ 成分のたい積物層厚さの総和として Eq. (8)で表 される。なお, Eq. (8) は Eq. (5)に Eq. (7) を代入する際に, Eq. (7)の分子と分母に $m L / \tan h m L$ を乗じて式を変形して導か れている。ここでは, Eq. (8) を細孔内たい積層分布関数（以 下，分布関数）と呼ぶ。

$$
\begin{aligned}
\lambda_{x}= & \sum_{i=1}^{n} \omega r_{0}\left[\frac{2-\sqrt{4-\left(1+\frac{2 m_{i} L}{\sin h 2 m_{i} L}\right) \frac{2 m_{i} L}{\tan h m_{i} L} \frac{V_{\mathrm{D} i}}{V_{0}}}}{1+\frac{2 m_{i} L}{\sin h m_{i} L}}\right] \times \\
& \frac{\cos h m_{i}(L-x)}{\cos h m_{i} L}
\end{aligned}
$$

Eq. (8)に $m_{i} L=1 / 100$ を代入すると, $\lambda_{x}$ が $x$ の位置にかかわ らず一定になる。すなわち, チイレ数が小さいとき, 反応律速 になるため, たい積物が細孔内に均一にたい積している状態を 表している。

$x$ 点に扔ける細孔半径 $\left(r_{x}\right)$ は分布関数によって計算される $\lambda_{x}$ から Eq. (9)によって求められる。したがって, コークおよ びメタルがたい積した使用済触媒の平均細孔半径 $\left(r_{A}\right)$ は Eq. (10) で与えられる。

$$
\begin{aligned}
& r_{x}=n-\lambda_{x} \\
& r_{A}=\frac{1}{L} \int_{0}^{L} r_{x} \mathrm{~d} x
\end{aligned}
$$

実際の触媒は細孔に分布をもち物性も様々であるため, 平均 細孔径モデルでたい積層厚さ入を近似するにはこれらの影響 

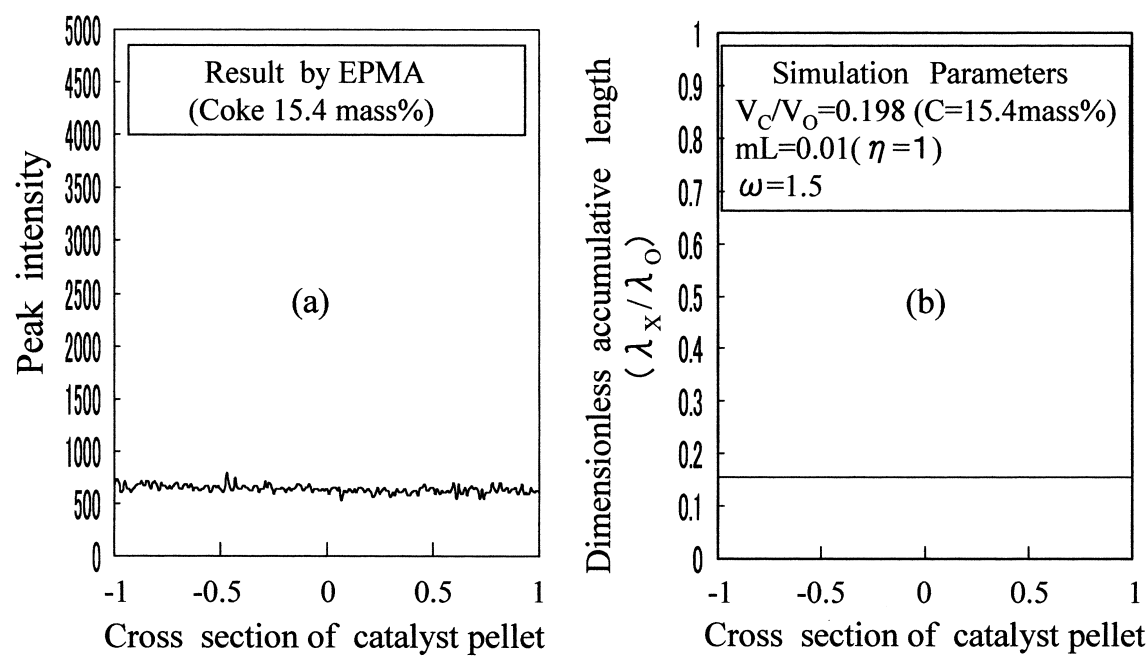

(a): Observed distribution. (b): Calculated distribution.

Fig. 3 Coke Distribution Curve within Pore of Catalyst Used in Commercial Equipment

を補正するパラメーターが必要と考えられた。分布関数ではこ れを補正するため, 触媒物性パラメーターとして Eq. (11)で定 義される補正係数 $\omega$ を導入した。 $\omega$ は, 実測された平均細孔 径半径 $\left(r_{\mathrm{A}}\right)_{\mathrm{obs}}$ と触媒有効係数を 1 として Eq. (10) から計算され る平均細孔半径 $\left(r_{\mathrm{A}}\right)_{\text {cal }}$ の比として求められる。すなわち，分布 関数にコーク $(i=1)$, バナジゥム $(i=2)$, ニッケル $(i=3)$ を代入し，これを合計して $\left(\lambda_{x}\right)_{\eta=1}$ を求め, Eq. $(10) よ り ~\left(r_{A}\right)_{\mathrm{cal}}$ を決定した。

$$
\omega=\left(r_{A}\right)_{\mathrm{cal}} /\left(r_{A}\right)_{\mathrm{obs}}
$$

さらに，分布関数ではたい積物の無次元容積を成分 $i$ のたい 積物容積 $\left(V_{\mathrm{D} i}\right)$ の総和と新触媒の細孔容積 $\left(V_{0}\right)$ の比として Eq. (12)のように定義した。ここで, $V_{\mathrm{V} i}$ は成分 $i$ のたい積物の 比容積, $M_{\mathrm{D} i}$ は $i$ 成分の単位新触媒質量あたりのたい積物質量 である。

$$
V_{\mathrm{D}} / V_{0}=\sum_{i=1}^{n} V_{\mathrm{D} i} / V_{0}=\sum_{i=1}^{n} V_{\mathrm{v} i} M_{\mathrm{D} i} / V_{0}
$$

触媒寿命 $\left(t_{\infty}\right)$ に達した時のたい積物容積の総和 $\left(V_{\mathrm{D}}\right)$ は各た い積物の蓄積速度 $\left(r_{\mathrm{D} i}\right)$ を $t=0$ から $t=t_{\infty}$ まで積分することに より Eq. (13)で得ることができる。

$$
V_{\mathrm{D}}=\sum_{i=1}^{n} V_{\mathrm{V}_{i}} \int_{0}^{t_{\infty}} \overbrace{i} \mathrm{~d} t
$$

筆者らは，既報9において，使用済触媒のコークおよびメ夕 ルたい積量と細孔容積の減少量との間に Eq. (14)の加成性が成 り立つと仮定して, それぞれの比容積を求めた。すなわち, Eq. (14) は Eq. (12)の定義においてコーク $(i=1)$, メタル $(i=$ 2), $V_{\mathrm{V} 1}=V_{\mathrm{C}}, V_{\mathrm{V} 2}=V_{\mathrm{m}}, V_{\mathrm{D}}=\Delta P V$ として求めたものである。

$$
\Delta P V=V_{\mathrm{C}} \Delta C+V_{\mathrm{m}} \Delta M
$$

ここで, $\Delta P V$ は細孔容積の減少量で $\left(V_{0}-V_{\mathrm{D}}\right)$ であり， $V_{\mathrm{C}}$ はコークの比容積, $\Delta C$ は単位触媒量あたりのコークたい積量, $V_{\mathrm{m}}$ はメ夕ルの比容積, $\Delta M$ は単位触媒量あたりのメ夕ルたい 積量である。これらの関係から求めたコークとメタルの比容積 は，使用した ARの性状に関係なく， $V_{\mathrm{C}}=0.8 \mathrm{~cm}^{3} / \mathrm{g}, V_{\mathrm{m}}=0.4$ $\mathrm{cm}^{3} / \mathrm{g}$ となった。コークおよびメタル比容積は触媒劣化の程度 や新触媒時の物性に影響を受けず，どの触媒でもほぼ一定であ り，コーク比容積はメタルのそれと比べて 2 倍以上になること を明らかにした。

\section{2. 分布関数によるコークおよびメタルたい積の解析結果}

3.1. で記したモデルの有効性を確かめるため, 商業装置で 1 年間使用した脱硫触媒（コークたい積量 $=15.4 \mathrm{mass} \%$ ）に適用 し, EPMA で観測されたたい積物の細孔内分布の実測値と比 較してFig. 3 に示した。使用済触媒の細孔内たい積層を分布 関数で解析するにあたっては, コークの比容積を $0.8 \mathrm{~cm}^{3} / \mathrm{g}$, メタルの比容積 $0.4 \mathrm{~cm}^{3} / \mathrm{g}$ を用いて, Eq. (14) より無次元たい積 物容積を求めた。また, 触媒物性パラメーター $\omega$ は Eq. (11) より決定した。

使用済触媒のたい積コークの EPMA 分析結果と分布関数に よる計算結果を Fig. 3 に示す。図の横軸は触媒の中心部を 0 として左方向半径を-1 $(-L)$, 右方向半径を $1(L)$ として無次 元距離で表している。コークは Fig. 3(a) に示すように, EPMAの分析結果から細孔内にほぼ均一にたい積していた。 コークたい積が細孔内で均一になるのは, コークが反応物と同 時に生成物からも生成するためと推察される。Fig. 3(b) は分 布関数で触媒有効係数を 1 として使用済触媒のコークたい積層 厚さを計算した結果である。得られたシミュレーションパラメ ーターを Fig. 3(b) に示した。図より分布関数で計算されたコ 一クたい積層はEPMAの結果と同様に細孔内に均一に分布し ており, 細孔径の減少に対するコークたい積の寄与分 $\left(\lambda_{\mathrm{C}}\right)$ は縦軸の無次元たい積層厚さより 0.16 であるとが分かる。 同様にして, メタルたい積層厚さについても実測曲線と計算曲 線の比較を行った。使用済触媒のたい積バナジウム（19.7 mass％）のEPMA 分析結果と分布関数による計算結果を Fig. 4 に示す。Fig. 4(a) に示す EPMAの結果より, バナジゥムは 触媒の外表面部近傍に偏析していることが分かる。このことは 本触媒に扮ける脱バナジウム反応が強い拡散抵抗を受けていた 

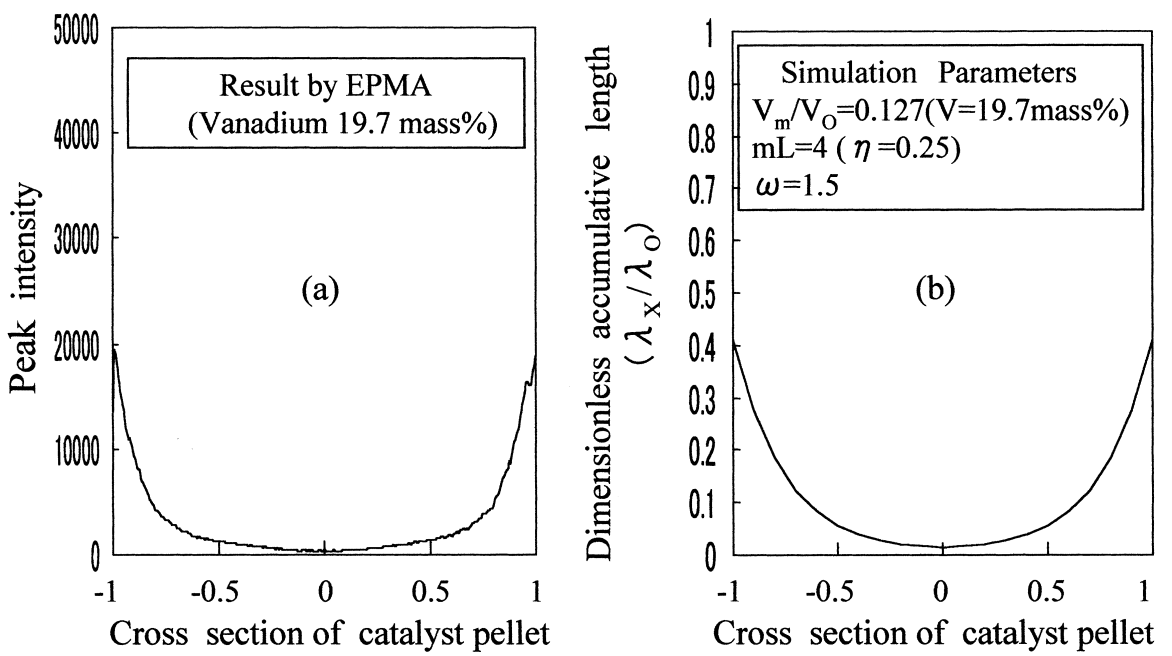

(a): Observed distribution. (b): Calculated distribution.

Fig. 4 Vanadium Distribution Curve within Pore of Catalyst Used in Commercial Equipment
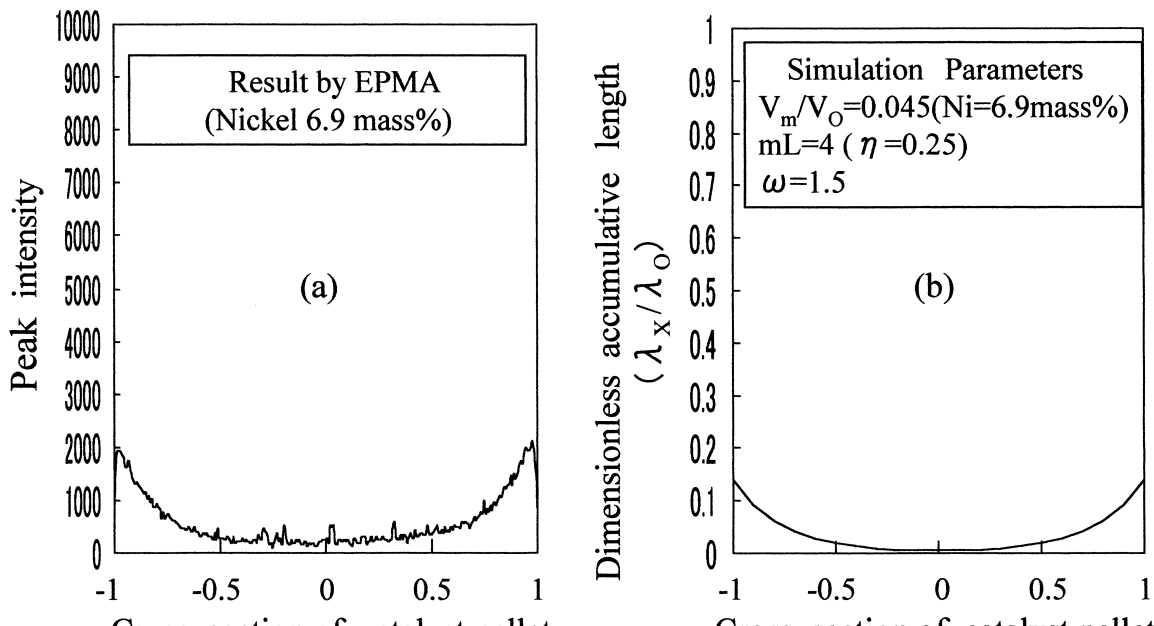

Cross section of catalyst pellet

Cross section of catalyst pellet

(a): Observed distribution. (b): Calculated distribution.

Fig. 5 Nickel Distribution Curve within the Pores of Catalyst Used in Commercial Equipment

ことを示している。Fig. 4(b) は，拡散抵抗を受けているとし て, 本触媒の水素化脱バナジウム反応の触媒有効係数を 0.25 としたときの計算結果である。計算結果は EPMAによる分析 結果の傾向とよく一致している。さらに, たい積ニッケル $(6.9$ mass％）の使用済触媒の EPMA 分析結果と分布関数の解析結 果をFig. 5 に示した。Fig. 5(a) より, ニッケルもバナジウム のたい積分布と同様に触媒外表面部近傍に偏析していた。触媒 有効係数を脱バナジウム反応と同じく 0.25 としたときの計算 結果は, Fig. 5(b) に示すようにEPMA 分析の傾向をよく表し ている。

EPMA は分析方法の特性から，峳密には定性分析であるた め, 計算結果との定量的な比較は難しいが, たい積物分布の傾
向を比較するには有効な方法である。本研究で提案した分布関 数を用い, 触媒有効係数を特定することによって, 触媒上への メタルたい積の分布を推定することが可能になった。

使用済触媒（コークたい積量＝15.4 mass\%，メタル $(\mathrm{V}+\mathrm{Ni})$ たい積量 $=26.6$ mass \% ）のコークおよびメタルたい積量を合わ せた細孔径分布を分布関数によって計算した結果を Fig. 6 に 示す。Fig. 6(a) は $m_{i} L=0.01(i=1,2,3)$ として計算した結果 であり, Fig. 6(b) は $m_{1} L=0.01, m_{2} L=m_{3} L=4$ として計算した 結果である。このとき, 触媒物性パラメーターとして, 前節の 結果から $\omega=1.5$ を用いた。Fig. 6(a) では, コークおよびメ夕 ルの触媒有効係数は 1 であり, コークおよびメタルは均一にた い積し, 計算から求められる無次元たい積層厚さは, 細孔半径 


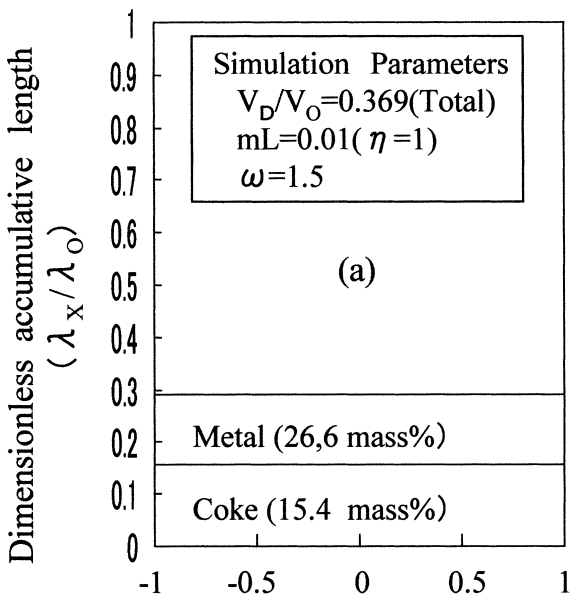

Cross section of catalyst pellet

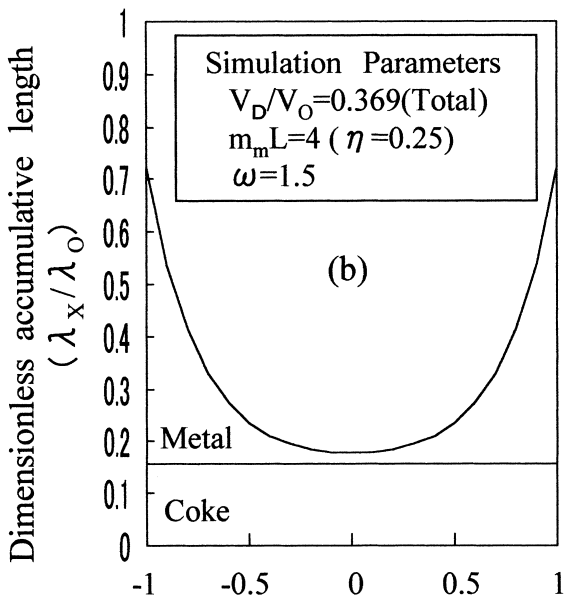

Cross section of catalyst pellet

Fig. 6 Coke and Metal Distribution Curve within the Pores of Catalyst Used in Commercial Equipment Calculated by Eq. (8)

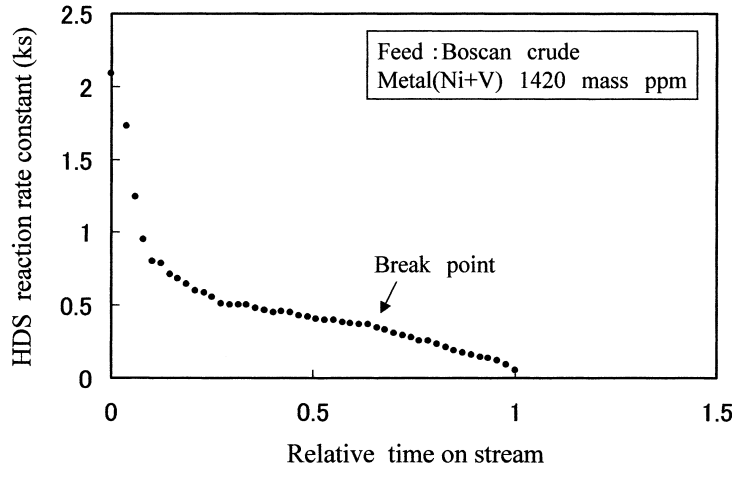

Fig. 7 Deactivation Test for Three Types of Catalyst System Accelerated by Using Boscan Crude
の $30 \%$ 程度である。この使用済触媒のメタルたい積質量はコ ークたい積質量より約 1.7 倍多いが，コークの比容積が $1 / 2$ の ため，両者の無次元たい積層厚さの寄与分は同程度になった。 これに対して, Fig. 6(b) ではコークの有効係数は 1 であるが, メタルの触媒有効係数が 0.25 となり, 細孔径の減少は一様で はなく，特に外表面部の無次元たい積層厚さは細孔半径の 7 割 程度に達する。不均一たい積の場合の細孔径は中心部方向へ行 くに従い，均一たい積の場合より大きくなるので，Eq. (10)で 計算される平均細孔半径 $\left(r_{A}\right)$ は均一たい積の場合とほぼ同一 になる。

このように細孔容積が残っているにもかかわらず，触媒活性 が急激に減少する変曲点が現れ，これを Break point と呼ぶ。 この Break point の計算法については, 既報に詳細に記したが8), 要約すれば反応律速から拡散律速に変化する点である。この Break point が観察される理由は, 細孔入口付近の閉そくによっ て説明される。したがって, Break point は平均細孔径ではなく, 細孔入口部の細孔径の大きさで決まることが確認された。

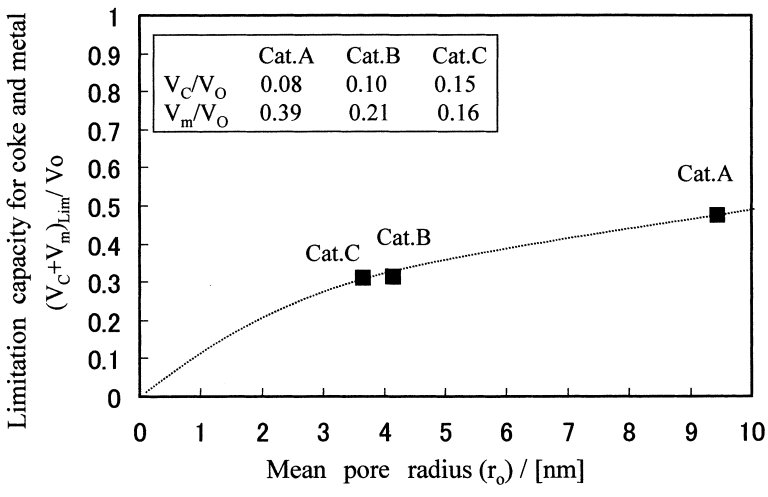

Fig. 8 Effect of Mean Pore Radius on Dimensionless Pore Volume at EOR for HDS of Boscan Crude

\section{3. 分布関数による細孔閉そくのシミュレーション}

前節の解析結果から, 分布関数が触媒細孔内のコークおよび メ夕ル分布を定量するのに有効であることが確かめられた。分 布関数の有効性を確かめるため, 高圧固定床小型流通式反応装 置9)を用いて, メタル含有量の大きなボスカン原油の HDS 反 応を行った。前報で記した細孔径の異なる 3 種類の触媒を組み 合わせて用い, 反応温度を $395^{\circ} \mathrm{C}$ 一定にして HDS 反応を行い, 残余活性が $5 \%$ になるまで失活させた時点で反応を停止し使用 済触媒を回収した。

ボスカン原油による劣化加速試験における相対通油時間に対 する反応速度定数を Fig. 7 に示す。この結果はコークおよび メタルたい積に起因する典型的な触媒劣化挙動を表した。すな わち, 反応速度定数の挙動は SOR で急速に低下したのち MOR で安定し, EORで再び急激な低下を示した。眓より相対通油 時間が約 0.7 で細孔閉そく（Break point）が顕著になり，1で 触媒寿命に達した。

Fig. 8 は回収した触媒のコークおよびメタルたい積量から計 算された無次元限界たい積物容積と新触媒の平均細孔半径の関 


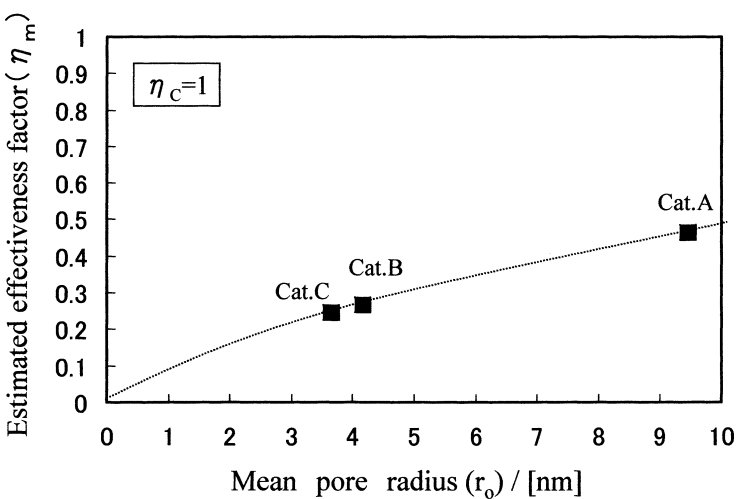

Fig. 9 Effect of Mean Pore Radius on Metal Effectiveness Factor at EOR for HDS of Boscan Crude

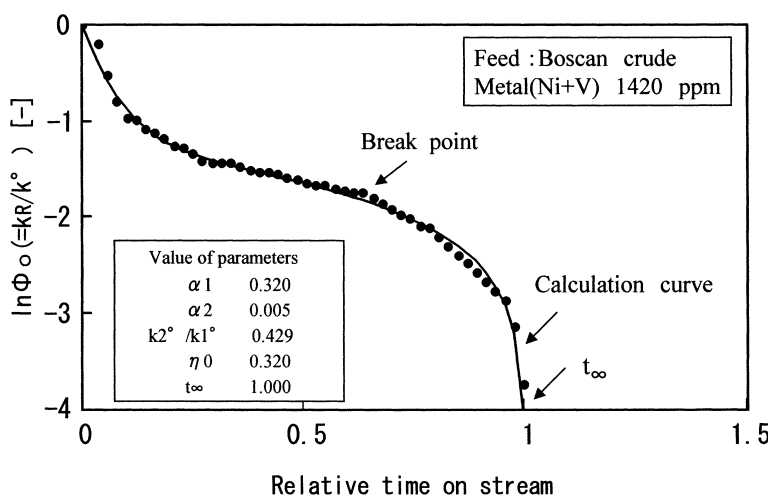

Fig. 10 Comparison of Calculated and Observed $\Phi_{0}$ in HDS for Boscan Crude

度から精度よく推定することが可能であり, 触媒設計や寿命推 定等に応用できる実用的なモデルであると考えられる。

\section{4. ま と め}

本研究では, 細孔内拡散理論を応用して, 細孔内にたい積し たコークおよびメタル分布を, 触媒物性とたい積物の物性值か らシミュレーションできる実用的な分布関数を導出した。本分 布関数を用いて平均細孔径とたい積物量の異なる使用済触媒を 解析した結果, 以下の知見を得た。

（1）使用済触媒のコークおよびメタルをEPMA で分析したと ころ,コークは細孔内に均一にたい積し, メタルは不均一にた い積していた。

（2）分布関数によるコークやメタル $(\mathrm{V}, \mathrm{Ni})$ 分布の計算結果 はEPMA 分析で観測されたたい積物分布を定性的に表現でき ることが分かった。

（3）分布関数は各種のたい積物に対して触媒物性（平均細孔 径・細孔容積）とたい積物の密度（比容積）から, 触媒有効係 数をパラメーターとして, 細孔内のたい積物分布を定量的に求 めることができた。

（4）細孔閉そくした触媒の解析結果から, 分布関数によって触 媒のコーク・メタル許容量を推定できることが確認された。

（5）分布関数から求めた触媒有効係数とコーク・メタル許容量 (触媒寿命) を総括劣化モデルに導入することにより, 触媒物 性から EOR での触媒劣化挙動を推定できることが確認された。 （6）分布関数は触媒設計や寿命推定等に応用できることが示唆 された。

メーターを実測值から求めて計算した。ただし，この劣化加速 試験では 3 触媒を均等量で組み合わせているため各触媒の有効 係数の加重平均值を $\eta_{0}$ とした。この解析ではHDS の代わりに メタルたい積物から特定した HDM の触媒有効係数を用いた が，計算值は SOR から EORのすべての領域で実測值とょく一 致している。このことはボスカン原油の水素化処理反応では HDS も HDM も拡散律速下で進行していることが考えられる。

以上の結果から, 細孔内拡散速度を平均細孔径モデルに応用 して導出した分布関数は触媒にたい積したコークやメタルなど の分布を, 触媒物性 (平均細孔径・細孔容積) とたい積物の密

\section{Nomenclatures}

\begin{tabular}{llr}
\multicolumn{3}{c}{ Nomenclatures } \\
$\Delta C:$ deposited coke on catalyst & {$[\mathrm{g} / \mathrm{g}]$} \\
$D \quad:$ effective diffusivity & {$\left[\mathrm{cm}^{2} / \mathrm{h}\right]$} \\
$k \quad:$ intrinsic first order rate constant & {$\left[\mathrm{h}^{-1}\right]$} \\
$L$ & $:$ characteristic size of catalyst pellet & {$[\mathrm{cm}]$} \\
$\Delta M:$ deposited metal $(\mathrm{Ni}+\mathrm{V})$ on catalyst & {$[\mathrm{g} / \mathrm{g}]$} \\
$m_{i} L:$ Thiele modulus for $i$ component & {$[-]$} \\
$r_{0}:$ mean pore radius of catalyst & {$[\mathrm{cm}]$} \\
$r_{\mathrm{D} i}:$ accumulation rate for $i$ component & {$[\mathrm{g} /(\mathrm{g} \cdot \mathrm{h})]$} \\
$V_{\mathrm{C}}:$ specific volume of coke & {$\left[\mathrm{cm}^{3} / \mathrm{g}\right]$} \\
$V_{\mathrm{D}}:$ specific volume of total deposits & {$\left[\mathrm{cm}^{3} / \mathrm{g}\right]$} \\
$V_{\mathrm{m}}:$ specific volume of metal & {$\left[\mathrm{cm}^{3} / \mathrm{g}\right]$}
\end{tabular}


$\left.\begin{array}{lc}V_{0}: \text { specific pore volume of fresh catalyst } & {\left[\mathrm{cm}^{3} / \mathrm{g}\right]} \\ <\text { Greeks }> & \\ \eta_{i} \quad: \text { effectiveness factor for } i \text { component } & {[-]} \\ \omega & : \text { physical parameter of catalyst defined by Eq. (10) }\end{array}\right]$

\section{References}

1) Tamm, P. W., Harnsburger, H. F., Bridge, A. G., Ind. Eng. Chem., Process. Des. Div., 20, 262 (1981).

2) Quann, R. J., Ware, R. A., Hung, C. W., Wei, J., Adv. Chem. Eng., 14, 95 (1988).

3) Newson, E. J., Ind. Eng. Chem., Process. Des. Dev., 14, 27 (1975).
4) Sahimi, M., Tsotsis, T. T., J. Catal., 96, 552 (1985).

5) Melkote, R. R., Jensen, K. F., Chem. Eng. Sci., 44, 649 (1989).

6) Takatsuka, T., Higashio, S., Hirohama, S., Wada, Y., Kajiyama, R., Prepr. Div. Pet. Chem. ACS, 40, 441 (1995).

7) Idei, K., Yamamoto, Y., Yamazaki, H., Kagaku Kogaku Ronbunshu, 21, 972 (1995).

8) Idei, K., Yamamoto, Y., Takehara, T., Kagaku Kogaku Ronbunshu, 24, 653 (1998).

9) Idei, K., Takahashi, T., Kai, T., J. Jpn. Peterol. Inst., 45, (5), 295 (2002).

10) Idei, K., Takahashi, T., Kai, T., J. Jpn. Peterol. Inst., 45, (5), 305 (2002).

要旨

\title{
水素化脱硫触媒の反応後期におけるコークおよびメタルたい積分布の推算
}

\author{
出井 一夫 ${ }^{\dagger 1)}$, 高橋 武重 ${ }^{\dagger 2)}$, 甲斐 敬美 ${ }^{\dagger 2}$ \\ †1) コスモ石油(株) 中央研究所, 340-0193 埼玉県幸手市権現堂 1134-2 \\ †2) 鹿児島大学工学部応用化学工学科, 890-0065 鹿児島市郡元 1-21-40
}

常圧残油を水素化脱硫触媒を用いて処理すると，反応の終期 （End of Run=EOR）において，目的とする脱硫率を得るため に必要な温度が急激に上昇する現象が観察される。この原因 は，触媒細孔入口にメタルがたい積して，反応物質の拡散を妨 げることによると説明されている。

本研究では，たい積物をコークとメタルの二つに分けて，活 性劣化に及ぼす寄与を推定するため, 細孔径の異なる 3 種類の 触媒を用いて, 水素化脱硫反応 (HDS) を行い, 生成するコー クおよびメタルのたい積パターンを EPMA で分析した。これ を定量的に表すため，細孔内にたい積するコークおよびメタル
の分布を与えるモデル式を構築した。このモデル式のパラメー ターとして, 触媒性状補正因子拉よびチイレ数（Thiele modulus）を用いることで，コークおよびメタルの分布をシミュレ ーションできることを示した。このモデル式を 1 年間商業装置 で使用した使用済触媒抢よびメタル含量の大きなボスカン原油 によりたい積させた上記 3 種類の触媒の細孔閉そくに適用し た。その結果, コークのチイレ数を 0.01 , メ夕ルのそれを 4 程 度とすることで，細孔閉そくを再現できることを示した。この モデル式は触媒寿命の推定に有用であると考えられる。 